\title{
Cytotoxic Potential of Antioxidants from Tomatoes on Tumoral Cells
}

\author{
Diana CENARIU ${ }^{1}$, Adela PINTEA², Eva FISCHER-FODOR ${ }^{3}$, Mustafa N BUCAK ${ }^{4}$, \\ Mihai CENARIU ${ }^{5 *}$, Gianina CRIŞAN ${ }^{1}$ \\ ${ }^{1}$ Department of Pharmaceutical Botany. University of Medicine and Pharmacy "Iuliu Hatieganu" Cluj- \\ Napoca, 8 Victor Babes Street, 400012 Cluj-Napoca, Romania \\ ${ }^{2}$ Department of Biochemistry. University of Agricultural Sciences and Veterinary Medicine Cluj-Napoca, \\ 3-5 Calea Manastur, 400372 Cluj-Napoca, Romania \\ ${ }^{3}$ Research Department. Institute of Oncology "Prof.Dr.I.Chiricuta", 34-36 Republicii Street, 400015 Cluj- \\ Napoca, Romania \\ ${ }^{4}$ Department of Reproduction and Artificial Insemination. Selcuk University Konya, Alaaddin Keykubat \\ Campus, Konya, Turkey \\ ${ }^{5}$ Department of Animal Reproduction.University of Agricultural Sciences and Veterinary Medicine Cluj- \\ Napoca, 3-5 Calea Manastur, 400372 Cluj-Napoca, Romania \\ *Corresponding author: mihai.cenariu@usamvcluj.ro
}

Bulletin UASVM Veterinary Medicine 72(2) / 2015,

Print ISSN 1843-5270; Electronic ISSN 1843-5378

DOI:10.15835/buasvmcn-vm: 11594

\begin{abstract}
Tomatoes (Lycopersicon esculentum Mill.) are known to contain various antioxidants such as lycopene and other carotenoids, which were proven to have antineoplastic activity. The aim of the present study was to obtain and characterize a whole tomato extract in order to show the amount and type of antioxidants contained, as well as to assess the cytotoxic potential of such extracts on the HepG2 tumoral cell line. Tomato extracts were obtained using the light petroleum/ethyl acetate/methanol method and characterized by HPLC. HepG2 liver hepatocellular carcinoma cell line was grown in Eagle's Minimum Essential Medium (EMEM) supplemented with 10\% FBS. As soon as subconfluency was reached cells were transferred into 96 well plates and treated with serial dilutions of the tomato extract. Cytotoxicity of the extracts was assessed using the MTT dye, in comparison with untreated cells and IC50 was established. The extraction method proved to be a very efficient one, yielding significant amounts of carotenoid pigments, including lycopene, $\beta$-carotene, $\gamma$-carotene and others, as shown by the HPLC analysis. The antioxidants contained by the extracts showed significant cytotoxicity on HepG2 liver hepatocellular carcinoma cell line, being able to visibly inhibit cellular development in vitro. The present study showed the cytotoxic influence that antioxidants extracted from tomatoes exert on the in vitro development of a hepatocellular carcinoma cell line, opening new perspectives for in vivo studies, involving patients with hepatic cancer.
\end{abstract}

Keywords: antioxidants, carotenoids, cytotoxicity, tumoral cells

\section{INTRODUCTION}

Hepatocellular carcinoma (HCC) is a primary malignancy of the liver. It is now the third leading cause of cancer deaths worldwide, with over 500,000 people affected (Cicalese, 2014). In vitro animal and clinical studies suggest that lycopene, a nonprovitamin A carotenoid and a potent antioxidant, may attenuate the liver injury and possibly prevent the development of HCC (Seren et al., 2008). Tomatoes (Lycopersicon esculentum Mill.) contain plenty of lycopene, together with other antioxidants like ascorbic acid, $\alpha$-tocopherol, $\beta$-carotene and lutein (Kotkov et al., 2011) which were proven to have antineoplastic activity. HepG2 is a stable human tumour cell line derived from a liver hepatocellular carcinoma of a 15 year old 
Caucasian male. It has been used extensively for in vitro studies and is particulary suitable for cytotoxicity models (Dai et al., 1993; Scolastici et al., 2008; Xu et al., 2003).

The aim of the present study was to obtain and characterize a whole tomato extract in order to show the amount and type of carotenoid antioxidants contained, as well as to assess the cytotoxic potential of such extracts on the HepG2 tumoral cell line.

\section{MATERIALS AND METHODS}

Fully matured Menhir F1 tomatoes (Lycopersicon esculentum Mill.) were used in order to obtain the extract. They had been cultivated in greenhouse tunnels, respecting all requirements of organic farming. Extraction was performed three times with light petroleum/ethyl acetate/ methanol $(1: 1: 1, \mathrm{v} / \mathrm{v} / \mathrm{v})$ respecting the protocol described by Breithaupt and Schwack (2000). After addition of water and phase separation, the extract was filtered, evaporated and submitted to high performance liquid chromatography (HPLC) analysis, using a Shimadzu LC20 AT equipment with a SPD-M20A diode array detector and an YMC C30 column $(24 \mathrm{~cm} \times 4.6 \mathrm{~mm}, 5 \mu \mathrm{m})$. The mobile phases were represented by methanol and methyltert-butyl ether (MTBE). The DAD detector was set at $470 \mathrm{~nm}$ and the flow rate was $1 \mathrm{ml} / \mathrm{min}$. The retention time as well as UV-Vis spectrum of each carotenoid was compared to standard solutions (LGC Standards, UK). Concentration assessment was performed using a calibration curve obtained after plotting peak area versus concentration for five different concentrations of the standards, between $1-50 \mu \mathrm{g} / \mathrm{ml}$.

Human HepG2 liver hepatocellular carcinoma cell line was obtained from European Collection of Cell Cultures (ECACC, Salisbury, UK) and grown in Eagle's Minimum Essential Medium (EMEM) supplemented with 10\% FBS (Sigma Aldrich, St Louis, MO, USA). Cells were trypsinized at subconfluency, resuspended in culture medium and transferred into 96-well plates (Nunclon, Thermo Fischer Scientific, Waltham, MA, USA), at a density of $15 \times 10^{3}$ cells/well. Each well contained $190 \mu \mathrm{l}$ of culture media. Cells were incubated at $37^{\circ} \mathrm{C}, 5 \% \mathrm{CO} 2$ and saturated humidity for 24 hours, until attachment occurred. At this moment, $10 \mu \mathrm{l}$ of the carotenoid extract dissolved in tetrahydrofuran (THF, Sigma) was added to each well. The serial dilutions of the carotenoid extract were performed taking into consideration only the all-trans lycopene content of the extract, and ignoring the other carotenoids, so the final concentration in cell culture medium was between $0.5 \mu \mathrm{M}$ and $200 \mu \mathrm{M}$ all-trans lycopene. These serial dilutions were used in order to establish the inhibitory concentration 50 (IC50) of the carotenoid extract using the MTT assay.

The cytotoxic effect of the tomato extract was determined by colorimetry using the MTT dye (3-(4,5-dimethylthiazol-2-yl)-2,5-diphenyltetrazolium bromide, Sigma Aldrich, St Louis, MO, USA). Viable cells have the abilty to transform MTT into an insoluble compound (formazan) due to mitochondrial enzymatic activity. Formazan crystals were solubilized in dimethylsulphoxyde (DMSO, Titolchimica, Italy), followed by photocolorimetric measurement at $570 \mathrm{~nm}$, with a Synergy 2.0 microplate reader (BioTek, Winooski, USA). All analysis were performed in triplicate. IC50 values were obtained using a sigmoidal dose-response curve, with a $95 \%$ confidence. THF treated cells were used as negative control.

Data was analyzed using the Graph Pad Prism 5 biostatistics software (from GraphPad Software, La Jolla, USA).

\section{RESULTS AND DISCUSSION}

The extraction method yielded a satisfactory amount of carotenoids, and proved to be very suitable for this purpose. Also, HPLC-PDA analysis allowed us to easily and precisely characterize the extract, as expected.

The total carotenoid content of tomatoes was $12.31 \mathrm{mg} / 100 \mathrm{~g}$. The best represented compound was all-trans lycopene $(6.84 \mathrm{mg} / 100 \mathrm{~g})$. The other carotenoids were in smaller amounts, as follows: $\beta$-carotene $2.96 \mathrm{mg} / 100 \mathrm{~g}, \gamma$-carotene 1.44 $\mathrm{mg} / 100 \mathrm{~g}$, lycopene epoxide $(0.34 \mathrm{mg} / 100 \mathrm{~g})$ and cis-lycopene (0.73 mg/100 g) (Tab. 1, Fig. 1).

The MTT assay yielded significant results when the tomato extract was added in the culture medium as compared to the negative control (THF treated cells). All analysis were performed in triplicate and the IC50 values found for each determination were comparable, without statistically significant differences between them. The median IC50 value was $84,98 \mu \mathrm{M}$ all-trans lycopene, while the standard error of the mean (SEM) for the three determinations was 3.57 
Tab. 1. Carotenoid composition of the tomato extract by HPLC-PDA (peaks are shown in Fig.1)

\begin{tabular}{cccc}
\hline Peak no. & Compound & Retention time $(\mathrm{min})$ & $\begin{array}{c}\text { Amount } \\
(\mathrm{mg} / 100 \mathrm{~g})\end{array}$ \\
\hline 1 & $\beta$-Carotene & 28.4 & 2.96 \\
\hline 2 & $\gamma$-Carotene & 39.3 & 1.44 \\
\hline 3 & Lycopene epoxide & 44.3 & 0.34 \\
\hline 4 & All-trans Lycopene & 48.8 & 6.84 \\
\hline 5 & Cis-Lycopene & 49.3 & 0.73 \\
\hline
\end{tabular}

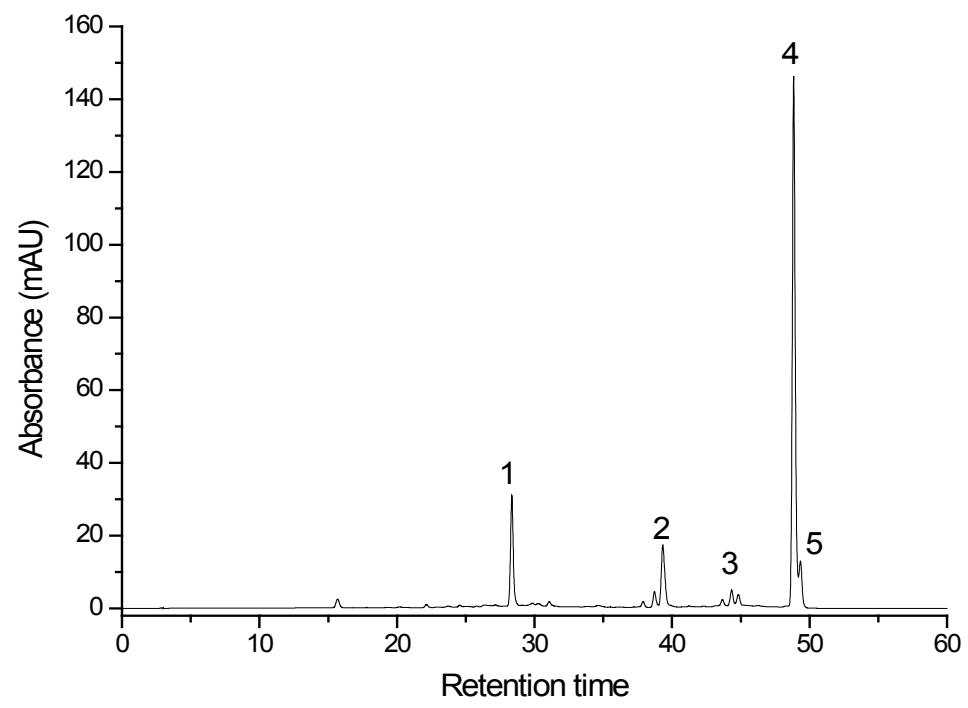

Fig. 1. Chromatogram obtained after HPLC-PDA separation of carotenoids from the tomato extract

(Fig.2). On the other hand, when compared to the negative control, the differences were very significant, demonstrating an obvious negative impact of the carotenoid extract on the HepG2 tumoral cell line (unpaired t-test, one tailed $p$ value $<0.05$ ).

Further studies are needed to demonstrate the antioxidant potential of the tomato carotenoids on the hepatocellular carcinoma cell line (HepG2) as well as to prove the capability of these antioxidants to induce apoptosis and inhibit the development of tumoral cells. Another important issue would be to demonstrate the molecular pathways modulated by tomato carotenoids, in order to fully understand their cytotoxic effect.

The work of other authors has shown the antioxidant and cytotoxic potential of lycopene on various tumours. Ilic (2014) reviewed the role of lycopene in inhibiting prostate cancer, revealing a statistically significant correlation between tomato consumption and the decrease of cancer risk. Bilecová-Rabajdová et al. (2013) also pointed out the role of lycopene as a chemo-protective agent against the neoplasic disease.

Lung cancer development was also shown to be inhibited by tomato lycopene (Palozza et al., 2011) as well as colorectal adenocarcinoma (Slattery et al., 2012). Moreover, breast cancer (Gloria et al., 2014) as well as pituitary adenoma (Haddad et al., 2013) were negatively influenced by tomato-extracted lycopene.

To our knowledge, this is the first study that shows the influence of tomato-extracted carotenoids on hepatocellular carcinoma cells, namely the HepG2 cell line.

One of the most commonly observed pathway that is modulated by lycopene in tumoral cells is NF- $\mathrm{kB}$. At the molecular level, most types of human tumors isolated from patients had abnormalities in the NF-kB signaling pathway, which is constitutively active (Jing and Lee, 2014). Therefore, the genes responsible for cell 


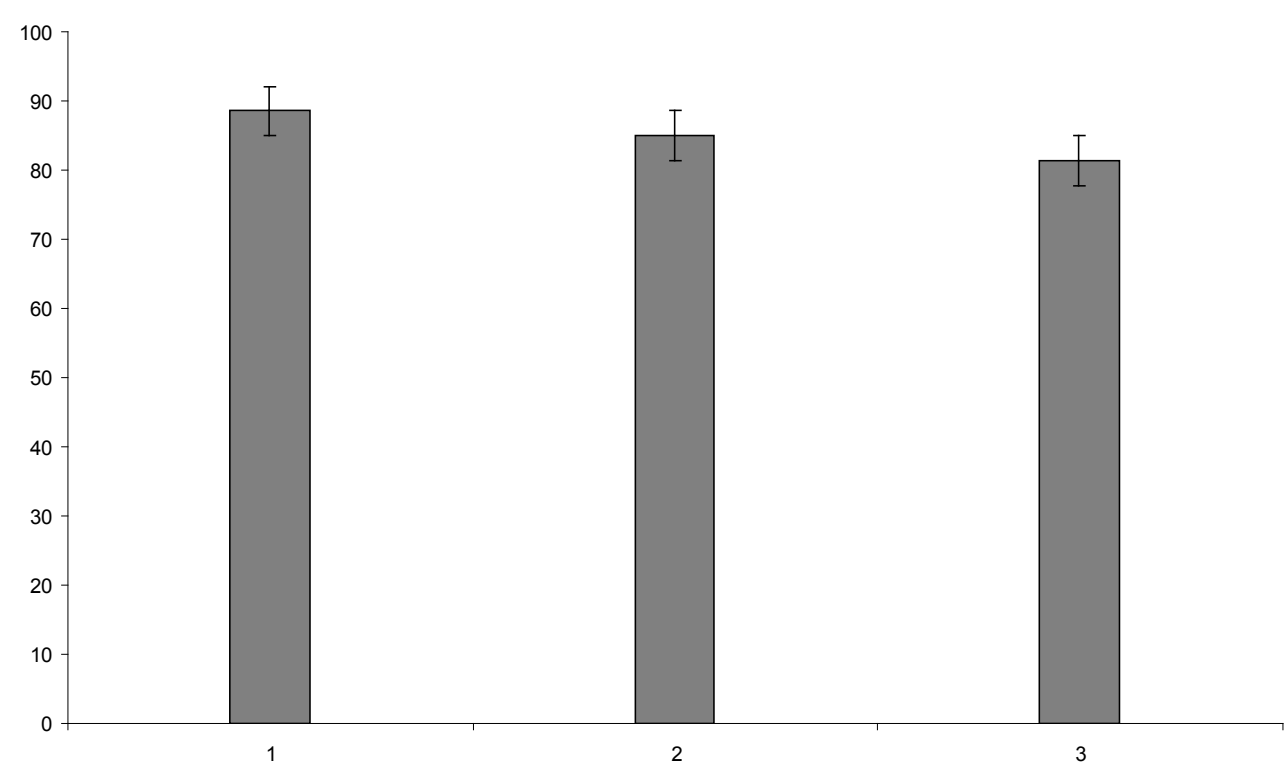

Fig. 2 Graphic representation of cell viability, showing the IC50 concentrations obtained after performing the MTT assay

proliferation become active, as well as preventing phenomena that would normally lead to cell death by apoptosis (Ledoux and Perkins, 2014).

Blocking the NF-kB pathway stops cell proliferation, induces apoptosis and makes the cancer cell more susceptible to antitumor agents. Preliminary studies have demonstrated that $\beta$-carotene as well has the ability to modulate NF-kB signaling pathway by means of a redox mechanism to tumor cells (Palozza et al., 2003).

\section{CONCLUSION}

The extraction method used in our study proved to be a very efficientone, yielding significant amounts of carotenoid pigments, including lycopene, $\beta$-carotene, $\gamma$-carotene and others, as shown by the HPLC analysis. The antioxidants contained by the extracts showed significant cytotoxicity on HepG2 liver hepatocellular carcinoma cell line, being able to significantly inhibit cellular development in vitro. Therefore, our study showed the cytotoxic influence that antioxidants extracted from tomatoes exert on the in vitro development of a hepatocellular carcinoma cell line, opening new perspectives for other in vitro as well as in vivo studies, involving patients with hepatic cancer.

Acknowledgments. This paper was published under the frame of European Social Found, Human Resources Development Operational Programme
2007-2013, project no. POSDRU/159/1.5/S/ 136893.

\section{REFERENCES}

1. Bilecová-Rabajdová M, Birková A, Urban P, Gregová K, Durovcová E, Mareková M (2013). Naturally occurring substances and their role in chemo-protective effects. Cent Eur J Public Health 21(4):213-219.

2. Breithaupt DE, Schwack W (2000). Determination of free and bound carotenoids in paprika (Capsicum annuum L.) by LC/MS. Eur Food Res Technol 211:52-55.

3. Cicalese L (2014). Hepatocellular Carcinoma. Medscape References. Drugs, Diseases and procedures. Available at: http://emedicine.medscape.com/article/197319overview.

4. Dai Y, Rashba-Step J, Cederbaum AI (1993). Stable expression of human cytochrome P4502E1 in HepG2 cells: characterization of catalytic activities and production of reactive oxygen intermediates. Biochemistry 32:69286937.

5. Gloria NF, Soares N, Brand C, Oliveira FL, Borojevic R, Teodoro AJ (2014). Lycopene and Beta-carotene Induce Cell-Cycle Arrest and Apoptosis in Human Breast Cancer Cell Lines. Anticancer Res 34(3):1377-1386.

6. Haddad NF, Teodoro AJ, Leite de Oliveira F, Soares N, de Mattos RM, Hecht F, Dezonne RS, Vairo L, Goldenberg RC, Gomes FC, de Carvalho DP, Gadelha MR, Nasciutti LE, Miranda-Alves L (2013). Lycopene and beta-carotene induce growth inhibition and proapoptotic effects on ACTH-secreting pituitary adenoma cells. Plos One 8(5):112.

7. Ilic D (2014). Lycopene for the prevention and treatment of prostate disease. Recent Results Cancer Res 202:109114. 
8. Jing H, Lee S (2014). NF-кB in Cellular Senescence and Cancer Treatment. Mol Cells 37(3):189-195.

9. Kotkov Z, Lachman J, Hejtmnkov A, Hejtmnkov K (2011). Determination of antioxidant activity and antioxidant content in tomato varieties and evaluation of mutual interactions between antioxidants. LWT - Food Sci \& Technol 44:1703-1710.

10. Ledoux AC, Perkins ND (2014). NF- $\kappa B$ and the cell cycle. Biochem Soc Trans 42(1):76-81.

11. Palozza P, Serini S, Torsello A, Di Nicuolo F, Piccioni E, Ubaldi V (2003). Beta-carotene regulates NFkappaB DNAbinding activity by a redox mechanism in human leukemia and colon adenocarcinoma cells. J Nutr 133:381-388.

12. Palozza P, Simone RE, Catalano A, Mele MC. (2011). Tomato lycopene and lung cancer prevention: from experimental to human studies. Cancers 3(2):2333-2357.

13. Scolastici C, Alves de Lima RO, Barbisan LF, Ferreira ALA, Ribeiro DA, Salvadori DMF (2008). Antigenotoxicity and antimutagenicity of lycopene in HepG2 cell line evaluated by the comet assay and micronucleus test. Toxicol in vitro 22(2):510-514.

14. Seren S, Mutchnick M, Hutchinson D, Harmanci O, Bayraktar Y, Mutchnick S, Sahin K, Kucuk O (2008). Potential role of lycopene in the treatment of hepatitis $C$ and prevention of hepatocellular carcinoma. Nutr Cancer 60(6):729-735.

15. Slattery ML, Lundgreen A, Welbourn B, Wolff RK, Corcoran C (2012). Oxidative balance and colon and rectal cancer: interaction of lifestyle factors and genes. Mutat Res Jun 1 734(1-2):30-40.

16. Xu Y, Leo MA, Lieber CS (2003). Lycopene attenuates arachidonic acid toxicity in HepG2 cells overexpressing CYP2E1. Biochem Biophys Res Commun 303:745-750.

17. Zu K, Mucci L, Rosner BA, Clinton SK, Loda M, Stampfer MJ, Giovannucci E (2014). Dietary lycopene, angiogenesis, and prostate cancer: a prospective study in the prostatespecific antigen era. J Natl Cancer Inst 106(2):10. 